\title{
SOFT SKILLS IN DESIGN EDUCATION, IDENTIFICATION, CLASSIFICATION AND RELATIONS: PROPOSAL OF A CONCEPTUAL MAP
}

\author{
Ana Paula Nazaré de FREITAS and Rita Assoreira ALMENDRA \\ Universidade de Lisboa, Faculdade de Arquitetura, CIAUD
}

\begin{abstract}
The article brings a conceptual map of soft skills in design education. This study is quantitative and qualitative research which was carried out through a survey with open and closed questions that involved 93 teachers of Superior Design Courses in 26 countries. The survey results were combined with a literature review analysis aimed at defining constructs and identifying their relationships. Finally, we propose a classification for soft skills as Collective/Individual and CognitiveMetacognitive/Interpersonal-Social. Additionally, we created a concept map about the soft skills in Design Education, showing the classification and the relations between the skills. In our research, we identify some relations that show gateways skills and high order skills as well as the relations between different groups of skills.
\end{abstract}

Keywords: Soft skills, design education, $21^{\text {st }}$ Century skills, higher education

\section{INTRODUCTION}

Soft skills are interpersonal, social, and emotional skills. They are transversal to various fields of knowledge and life and are also referred continuously as differentiators in the contemporary context [1], [2]. They are often related to the ability to work in groups, to thinking systematically, to collaborate, to develop self-regulation and socio-emotional skills.

We based this study on the results of a systematic review of literature carried out previously [3]. In this review, we analysed the soft skills linked to design studies that resulted in the identification of 49 skills, from which we point out the 17 most cited skills and added three skills identified by the OECD [4] as necessary to face the challenges of the $21^{\text {st }}$ Century.

The soft skills included in the study are presented in Table 1.

Table 1. Soft Skills included in this study

\begin{tabular}{|l|}
\hline $\begin{array}{l}\text { Communication: to understand and make oneself understood through exchanges of } \\
\text { messages; [13] }\end{array}$ \\
\hline $\begin{array}{l}\text { Critical Thinking: To reason well, to construct and evaluate various arguments, data, reasons, } \\
\text { and inferences. [14] }\end{array}$ \\
\hline Creativity: To go beyond what exists today and to generate and implement new ideas. [15] \\
\hline Problem Solving: To overcome obstacles and move from an initial state to a target state. [16] \\
\hline Curiosity: The desire to learn or know about everything; Ability to be inquisitive. [17] \\
\hline $\begin{array}{l}\text { Research and Exploration: Multifaceted competence which allows to know objective reality } \\
\text { through scientific instruments, and to have reliable information about it. [18] }\end{array}$ \\
\hline Decision Making: To follow normative principles when making decisions. [19] \\
\hline $\begin{array}{l}\text { Open-Mindedness: To be receptive to emerging possibilities, to share ideas and to consider } \\
\text { different perspectives. [20] }\end{array}$ \\
\hline $\begin{array}{l}\text { Systematic Thinking: The ability to observe, think, model, simulate, analyse, design, and } \\
\text { synthesise components, functions, connections, structures, inter-relationships and dynamics } \\
\text { between disciplines, functions, organisations, people, trends, and cultures.[9] }\end{array}$ \\
\hline $\begin{array}{l}\text { Empathy: Ability to take on the role of the other person and imagine the situation from their } \\
\text { perspective.[21] }\end{array}$ \\
\hline Collaboration The ability to participate in a process of shared creation. [22] \\
\hline
\end{tabular}




\begin{tabular}{|l|}
\hline Participation: Ability to participate in or be involved in something [23] \\
\hline $\begin{array}{l}\text { Flexibility/Adaptability: The ability to produce thoughts from different perspectives or to } \\
\text { change approaches to problem solving. [24] }\end{array}$ \\
\hline Learn to Learn: Ability to pursue and persist learning, to organise one's own learning. [25] \\
\hline $\begin{array}{l}\text { Team-working: The ability to work together, communicate effectively, anticipate, and meet } \\
\text { each other's demands, and inspire confidence, resulting in coordinated collective action. [26] }\end{array}$ \\
\hline $\begin{array}{l}\text { Self-direction/ Self-management: Ability to regulate your emotions, thoughts, and behaviour } \\
\text { effectively in different situations. [27] }\end{array}$ \\
\hline $\begin{array}{l}\text { Ethic/Compromise: The ability and willingness to be moral, to consider the needs, goals, and } \\
\text { perspectives of others in their own decisions. [28] }\end{array}$ \\
\hline Judgement: The ability to form valuable opinions and make good decisions [29] \\
\hline Leadership: Ability to exert influence on others through behaviour or action. [30] \\
\hline $\begin{array}{l}\text { Entrepreneurship: The ability to create new businesses, products, services, values and/or a } \\
\text { state of mind that thrives on innovations with the potential to improve the lives of many } \\
\text { people/customers.[31] }\end{array}$ \\
\hline
\end{tabular}

This research aimed to understand the perception of design teachers about the importance of Soft Skills in Design, measuring the importance and weight that each one attributes to each of the proposed skills. We also carried out a survey on the methods that professors use to teach these skills and classified them. With the results we created a conceptual map about Soft skills in the Design Education that brings a classification as well as a visualisation of their relations.

\section{METHODS}

This is a mixed methods research - quantitative and qualitative. It has been developed through a literature review combined with the application of a questionnaire survey.

The survey was mainly composed of close-ended questions of scale, where the design teachers were asked to assess the level of contribution of each skill to the teaching subjects in the design course. These questions used the Likert scale and asked teachers to assess the level of importance of the skills for the subjects they taught, indicating 1 for not contributing, 2 for contributing little, 3 for contributing sometimes, 4 for contributing and 5 for contributing a lot. The last part of the questionary asked if the teachers used any methodological practices that they felt enable opportunities for teaching soft skills and if so, the teacher was asked to describe the practice. In this last question, the answers were open. The sample was non-probabilistic and was composed of professors who work in higher education courses of Design.

\section{RESULTS}

93 responses of 26 countries were received. The countries that were most cited were Brazil and Portugal representing $49 \%$ of the sample.

The question that sought the evaluation of the average ranking of soft skills asked teachers to estimate the contribution of each of the skills to the subjects they taught. From the statistical analysis done with the SPSS software, the closer the Mean is to 5, the higher the evaluation of the attribute. (showed in Table 2)

Table 2. Ranking of Contributions of Soft Skills in Design Education.

\begin{tabular}{|c|c|c|c|c|}
\hline & \multicolumn{3}{|c|}{ N Min.Max.MeanSD } & Variance \\
\hline Communication Skills & 932 & 5 & 4.66 .667 & .446 \\
\hline Critical thinking & 932 & 5 & 4.65 .702 & .492 \\
\hline Research and exploration & 932 & 5 & 4.58 .727 & .529 \\
\hline Creativity & 932 & 5 & 4.54 .760 & .577 \\
\hline Problem Solving & 931 & 5 & 4.52 .816 & .665 \\
\hline Curiosity & 931 & 5 & 4.43 .914 & .835 \\
\hline Decision Making & 931 & 5 & 4.39 .794 & .631 \\
\hline Open-mindedness & 932 & 5 & $4.32 \quad .810$ & .656 \\
\hline Systemic thinking & 932 & 5 & 4.29 .879 & .773 \\
\hline Empathy & 931 & 5 & $4.28 \quad .982$ & .964 \\
\hline
\end{tabular}




\begin{tabular}{crrrccc} 
Participation & 93 & 2 & 5 & 4.26 & .793 & .628 \\
Flexibility/adaptability & 93 & 2 & 5 & 4.26 & .779 & .607 \\
Collaboration & 93 & 1 & 5 & 4.25 & .928 & .862 \\
Learn to learn & 93 & 1 & 5 & 4.18 & 1.042 & 1.086 \\
Teamwork & 93 & 1 & 5 & 4.15 & .966 & .934 \\
Self-direction/ Self-management93 & 2 & 5 & 4.05 & .889 & .791 \\
Ethic/compromise & 93 & 1 & 5 & 4.02 & .944 & .891 \\
Judgement & 93 & 1 & 5 & 3.69 & 1.063 & 1.130 \\
Leadership & 93 & 1 & 5 & 3.52 & 1.028 & 1.057 \\
Entrepreneurship & 92 & 1 & 5 & 3.27 & 1.178 & 1.387 \\
Valid N (listwise) & 92 & & & & & \\
\hline
\end{tabular}

\section{Discussion}

The research results show that teachers ranked the soft skills with high rates for the design practice. Among the 20 skills, none received an average ranking lower than 3. Only three skills received an average rating lower than 4 (Judging, Leadership and Entrepreneurship).

Concerning skills that emerge as significant contributors to design courses, there is the prevalence of cognitive and individual skills (in detriment of social and collective ones). Critical Thinking, Creativity, Problem Solving and Curiosity appear between second and fifth place. In the first place, Communication skills seem to be unanimous, as it also came first in the previous systematic review. Despite this, we identified an inconsistency in the teachers' discourse regarding the Team-working competence, which appeared in the average ranking in 15th place, but emerged in second place in the subjective answers. The teaching practices identified by teachers as enabling the development of soft skills point to constructivist-based pedagogies, student-centred and active methodologies. In order to improve the systematisation of knowledge about soft skills, we propose a classification of competences. This classification was created from the establishment of 2 sets: Skills that are performed mostly collectively versus skills performed mostly individually; we call this set Collectivel Individual. The other classification was Cognitive/Metacognitive skills and Interpersonal/Social skills. In both groups, we also identified the need to create two sub-groups: The Gateway Competences group and the High-order Competences group. The first group is composed of prior, initial skills which are necessary for the development of more elaborate, complex skills.

Based on these four types of classification, we have proposed the construction of a conceptual map, intending to clarify the sets, as well as the relationships identified between the skills in a visual way.

\subsection{Relations between skills}

The literature review carried out revealed an interconnection between the competencies. By analysing the definitions, it was possible to establish links and interconnect them. The first link that can be indicated results from the definitions of Curiosity, Research and Exploration, Judgment, Decision Making, Open-Mindedness, Creativity, Flexibility, Systematic Thinking and Critical Thinking. Some authors demonstrate the sequential and conditional character of some of these competencies. [5] [6]. It is possible to establish sets and, from those sets, to realise that for the development of the competence of Critical Thinking, it is essential to have previously developed the other competencies mentioned above. In this argumentative direction, we defend that Critical Thinking is a more complex competence and needs the development of other skills, because the development of Critical Thinking occurs or is made possible by the development of previous skills. Critical Thinking enjoys a prominent status in contemporary educational goals and ideals and is considered a fundamental model and underlying objective of Western education [7]. This can explain why this competence has been widely mentioned by educators, as well as the previous or related competences. Critical Thinking has also a direct relationship with Creativity and is a necessary competence for Creativity to be realised [7].

It is possible to establish the relationships between Flexibility, a necessary competence for Creativity, Curiosity, and Open-Mindedness (OM), the latter one is a timely and valuable competence for divergent thinking. From Socrates to contemporary education theorists, OM competence is considered essential for learning [8]. More recent researchers argue that OM is critical to assessing the mental models of individuals, which are deeply held beliefs or conceptions that can confine them to familiar patterns of thinking and acting. 
It is also possible to create the relationship between Systematic Thinking, Creativity, and Problem Solving, bearing in mind that systematic thinking is ultimately aimed at understanding problems. Systemic thinking draws from diverse disciplines to provide a holistic method for dealing with problems in any discipline. It is scientifically grounded in systems theory and a wide variety of transdisciplinary supporting principles providing a discipline-agnostic approach to address messes [9].

The competence of Research and Exploration is also preceded by the competence of Curiosity, so they are "Gateway Competencies"[10], i.e., introductory competences that induces others. Exploration and research, for example, derive from Curiosity [11]. The competence of research and the capacity to explore also seem to have this characteristic to lead to other competencies, such as Trial, Decision Making and Critical Thinking. It is not easy to separate these competencies objectively because they seem to be deeply intertwined one to the other.

The relationship between Ethics and Critical Thinking can also be established if we think that the construction of ethical thinking involves the cultivation of rational thinking since the competence of Ethics is realised as a construction of a critically reflexive morality [12].

Abut the cognitive self-regulatory skills, Learning to Learn and Self-Management skills are also related. Self-Management contains the Learning to Learn competence. Both benefit from Critical Thinking, which is a necessity for the development of Self-regulatory competence.

The competences that we call Social/Interpersonal also maintain relationships both with each other and with cognitive competences. The need for Critical Thinking and Ethics is unquestionable as "background" competencies for the optimal development of Communication, Empathy, Team-Working, Leadership, Entrepreneurship, Participation and Collaboration skills.

In this sense, it is possible to establish connections between Communication, Empathy, Collaboration, Participation and Team Working Skills. The ability to communicate well and develop listening skills can enhance Empathy skills. Consequently, being more empathetic makes it possible to be more inclined to the processes of collaboration and participation. Being able to communicate, listen, empathise, and collaborate allows to perform well in group work.

Finally, the skills that were assessed as less critical for Design were Leadership and Entrepreneurship. These skills also benefit from the above-mentioned competencies. It is expected that in the scope of Contemporary Design, which has a more collaborative character, leadership is a competence that has been assessed as less critical since the characteristic of collaboration is to be more horizontal and less hierarchical. Entrepreneurship also benefits from the competences, and a designer with this type of competence can act not only in his own business but also creating value, products, and services for society in a broad sense. This happens either through private business or through public services and social value, not driven by profit. It is likely that the very definition present in the common sense of these competencies influenced this result. Although they came in last place, the average rating of both was high at 3.54 and 3.46 respectively (out of a total of 5) which indicates an agreement on the contribution of these competencies to design of $70 \%$.

Based on these reflections from the literature review, a conceptual map (Figure 1) was created as a way to understand the sets discussed here as well as some of their main visual relationships. 


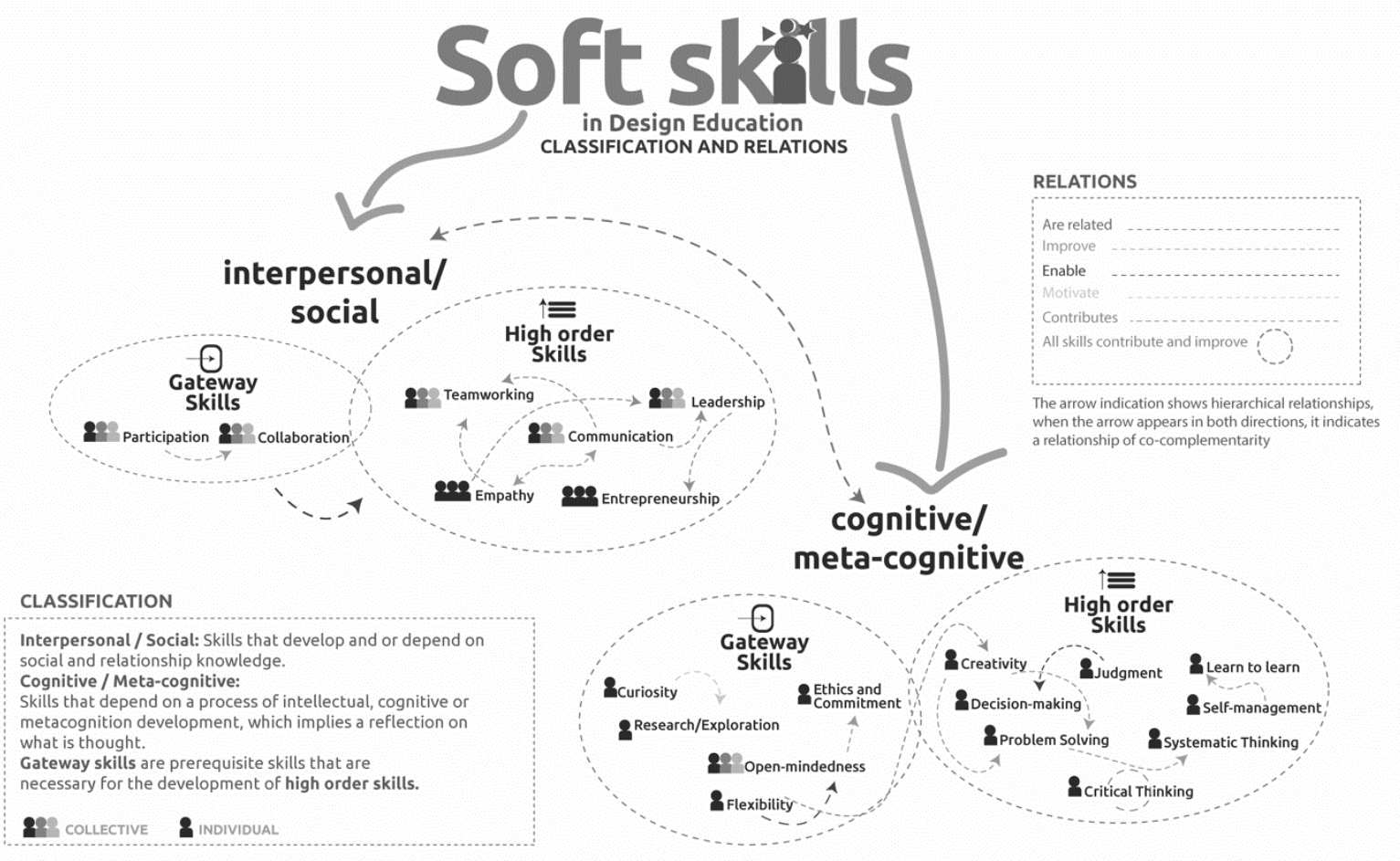

Figure 1. Concept Map: Soft Skills in Design Education

\section{CONCLUSIONS}

This research showed that the 20 soft skills identified in the systematic review have a high rate of importance for teachers in the areas where they work in Design. It was conceivable to determine the relationship and interconnection between the soft skills and to suggest, from the literature review and through the analysis of subjective responses, an interdependence between them.

The proposed classification, as well as the definition of the constructs projected in this article, may make it easier for teachers and students to identify the main soft skills in design education. It is possible to recognise which soft skills should be enhanced as initial skills in order to develop high-performance skills. This classification can be the initial way to indicate which methods can be applied and how to evaluate these skills according to the student's level of formation.

We are likely to develop strategies for teaching and to learn the gateways skills in the initial years, through the development of activities that can involve the students gradually and that increasingly require more skills in order to make them "scale-up" the soft skills of the conceptual map.

\section{ACKNOWLEDGEMENTS}

This work was financially supported by the Centro de Investigação em Arquitetura, Urbanismo e Design - CIAUD (Center for Research in Architecture, Urbanism and Design) of the Faculdade de Arquitetura da Universidade de Lisboa (Faculty of Architecture of the University of Lisbon) and by the Universidade do Estado do Pará - UEPA (State University of Pará), Brazil.

\section{REFERENCES}

[1] Succi C. and Canovi M. Soft skills to enhance graduate employability: comparing students and employers' perceptions. Studies in Higher Education, 2020, 45(9), 1834-47.

[2] Rychen D. S. Education 2030: Key competencies for the future, 2016 (Organization for Economic Cooperation and Development

[3] Freitas A. P. and Almendra R. A. Teaching and Learning Soft Skills in Design Education, Opportunities and Challenges: A Literature Review. In: 10th International Conference UNIDCOM/IADE - Senses \& Sensibility. Lisbon, November 2019. (in press)

[4] OECD. The Future of Education and Skills: Education 2030, 20189 (OECD

[5] van Laar E., van Deursen A., van Dijk J. and de Haan J. The Sequential and Conditional Nature 
of 21 st-Century Digital Skills. International Journal of Communication. 2019;13, 3462-3487.

[6] Bloom B. S. Taxonomy of Educational Objectives: The Classification of Educational Goals. In: Handbook I: Cognitive Domain. 1956 (David McKay Company, INC.).

[7] Siegel H. Critical Thinking. In: International Encyclopaedia of Education.; 2010. p. 141-5 (Elsevier).

[8] Lord M. Group learning capacity: The roles of open-mindedness and shared vision. Front Psychol. 2015;6(FEB):1-11.

[9] Gallón L. Systemic Thinking. In: Quality Education, 2019, Springer International Publishing. p. $1-11$.

[10] Kaye B. and Giulioni J. W. Curiosity: The Gateway Competency. Chief Learning Officer. Available from: https://www.chieflearningofficer.com/2013/01/18/curiosity-the-gatewaycompetency/ [accessed on 2020, 6, Jun.] (2013).

[11] Baxter A. and Switzky H. N. Exploration and Curiosity. In: Encyclopaedia of Infant and Early Childhood Development. Elsevier; 2008. p. 460-70.

[12] Borstner B. and Gartner S. Teaching ethics and critical thinking in contemporary schools. Problems of Education in the 21st Century, 2014, 61, 9-17.

[13] van Dijk J. A. G. M. and van Deursen A. J. A. M. Digital skills: unlocking the information society. 2014 (Palgrave Macmillan Ltd.).

[14] Paul R. and Elder L. Critical Thinking Competency Standards, 2007 (Foundation for Critical Thinking Press).

[15] Ward T. B. Cognition, creativity, and entrepreneurship. Journal of Business Venturing, 2004, 19(2), 173-88.

[16] University C. S. Problem Solving. Problem Solving. Chicago State University. Available: https://www.csu.edu/humanresources/empdev/documents/ProblemSolving.pdf [ Accessed on 2020, 06 Jun.] (2013).

[17] Baxter A. and Switzky H. N. Exploration and Curiosity. Encyclopaedia of Infant and Early Childhood Development, 2008. p. 460-70.

[18] Prokhorchuk A. The definition of "research competence." Edukacja - Technika - Informatyka. 2014, 1, 439-43.

[19] Parker A. M., Bruine de Bruin W., Fischhoff B., and Weller J. Robustness of Decision-Making Competence: Evidence from Two Measures and an 11-Year Longitudinal Study. Journal of Behavioural Decision Making, 2018, Jul;31(3), 380-91.

[20] Cegarra-Navarro J.G., and Cepeda-Carrión G. Why Open-mindedness Needs Time to Explore and Exploit Knowledge. Time \& Society. 2008; 17 (2-3), 195-215.

[21] OECD. The definition and selection of key competencies, 2005 (OECD).

[22] John-Steiner V. Collaboration. In: Encyclopaedia of Creativity. 2011. p. 222-5 (Elsevier;)

[23] Cambridge Dictionary. Participation. In: Cambridge Dictionary. 2020.

[24] Kaya F. Flexibility. In: Encyclopaedia of Creativity, 2020. p. 505-9 (Elsevier)

[25] European Parliament. Recommendation of the European Parliament of and of the Council of 18 December 2006 on key competences for lifelong learning. Official Journal of the European Union. 2006.

[26] Salas E. and Cannon-Bowers J. A. Teamwork and Team Training. In: International Encyclopaedia of the Social \& Behavioural Sciences. 2001 (Elsevier).

[27] Transforming Education. Introduction to Self-Management. 2014.

[28] Menzel D. C. Ethical Competence. In: Global Encyclopaedia of Public Administration, Public Policy, and Governance. 2016, 1-4 (Springer International Publishing)

[29] Cambridge Dictionary. Judgment. In: Cambridge Dictionary, 2020 (Cambridge).

[30] Mumford M. D. and Gujar Y. Leadership. In: Encyclopaedia of Creativity 2020. p. 33-8. (Elsevier)

[31] Parthasarathy N., Doboli S., and Paulus B. Entrepreneurship. In: Encyclopaedia of Creativity, 2 ed., 2011 (Elsevier) 